\title{
FABRICATION OF WORKING MODEL OF PLC BASED AGV FOR SERVING IN HOTEL
}

\author{
Spoorthiraj K N ${ }^{1}$, Shivashankara B $\mathbf{S}^{2}$, Sree Rajendra ${ }^{3}$, Sharath H K $^{4}$, VijayKumar G Thile \\ ${ }^{1}$ PG scholar, Dept. of Mech. Engg. Malnad college of Engineering, Karnataka, India \\ ${ }^{2}$ Assisstant Professor, Dept.of Mech. Engg., Malnad college of Engineering, Karnataka, India \\ ${ }^{3}$ Associate Professor, Dept.of Mech. Engg., Malnad college of Engineering, Karnataka, India \\ ${ }^{4}$ Assisstant Professor, Dept.of Mech. Engg., Malnad college of Engineering, Karnataka, India \\ ${ }^{5}$ Assisstant Professor, Dept.of Mech. Engg., Malnad college of Engineering, Karnataka, India
}

\begin{abstract}
Automated Guided Vehicles (AGVs) are among various advanced material handling techniques that are finding increasing applications today. They can be interfaced to various other production and storage equipments and controlled through an intelligent computer control system. The use of Automated Guided Vehicle is increasing day by day for the material transfer in production lines of modern manufacturing plants. The purpose is to enhance efficiency in material transfer and increase production.PLC controlled and wheel-based, automatic guided vehicles $(A G V)$ are load carriers that travel along the floor of a facility without an onboard operator or driver. Their movement is directed by a combination of software and sensor-based guidance systems. Because they move on a predictable path(line follower) with precisely controlled acceleration and deceleration, and include automatic obstacle detection used for waste management scenario at a hotel premises where the AGV will be used to collect the garbage and used utensils which are at the specific spots and dump it in the required dump sections.
\end{abstract}

Keywords: AGV, Automation, Material handling, PLC

\section{INTRODUCTION}

Line follower AGV is an unmanned vehicle that can follow a predefined path on the floor. The path is visible black line on a white surface (or vice-versa) or it can be invisible like a magnetic field. Sensing a line and maneuvering the robot to stay on course, while constantly correcting wrong moves using feedback mechanism forms a simple yet effective closed loop system. Feature of line follower:

- It follows a black strip on a floor and Stops if the line ends.

- It also stops if an obstacle is present, in its path and wait for some period time and moves when it clears.

\subsection{Problem Study}

In the today's hotel scenario the human employee is required to carry out the process of collecting the used utensils for the purpose of cleaning, this human intervention is partially has been reduced and replaced by the line follower AGV.

\subsection{Literature Survey}

Mudit Sharma et al developed an automated guided vehicle or automatic guided vehicle(AGV) is a mobile robot that follows markers or wires in the floor, or uses vision or lasers. However, the design of these systems is complex due to the interrelated decisions that must be made and the large number of system design alternatives that are available. In particular, the design of the AGVS control system can be quite challenging, and it can dramatically affect the system cost and performance. This paper presents a classification of automated guided vehicle systems developed from a control perspective. This classification is demonstrated on several example systems from the literature.[5] Suman Kumar das et al presented, automated guided vehicle plays a major role in engineering industries to improve the material handling technique for recent year. In this paper, it is focus on the design and different methodology of line follower automated guided vehicle (AGV) systems. This paper provides an overview on line follower AGV discusses recent technological developments. The essential components of line follower robot and their modification are described in this paper .[6] Atul Tiwari et al presented, Automated Guided Vehicles (AGV) are among various advanced material handling techniques that are finding increasing applications today. They can be interfaced to various other production and storage equipment and controlled through an intelligent computer control system. FMS are well suited for simultaneous production of a wide variety of part types in low volumes. Though the hardware of AGV's has made significant improvement in the field but the software control of the fleet still lacks in many applications.[4] Sigal Berman et al presented, a methodology for detailed evaluation of autonomous automated guided vehicles system (AGV) used for material handling. The defined performance measures include aspects from both multi-robot and AGV fields. The developed methodology provides a systematic way to model, experiment with, analyze, and compare different AGVS control methods. To demonstrate the methodology, it was applied to evaluate a recently developed decentralized AGVS control method. [3] Iris F.A. Vis et al designed an Automated 
guided vehicle (AGV) are used for the internal and external transport of materials. Traditionally, AGVs were mostly used at manufacturing systems. In fact, new analytical and simulation models need to be developed for large AGV systems to overcome large computation times, NP completeness, congestion, deadlocks and delays in the system and finite planning horizons. This work specify more specific research perspectives in the design and control of AGV systems in distribution, transshipment and transportation systems.[2] J. T. Udding et al presented a study on design and control of automated guided vehicle (AGV)systems, with the focus on the quayside container transport in an automated container terminal. AGVs from the routing problem. A routing algorithm is also constructed with the goal of minimizing the vehicle travel distances and the transportation time. The efficiency of the integrated design and control is demonstrated by computer simulations in terms of a set of defined measures of system performance. [1]

\section{METHODOLOGY}

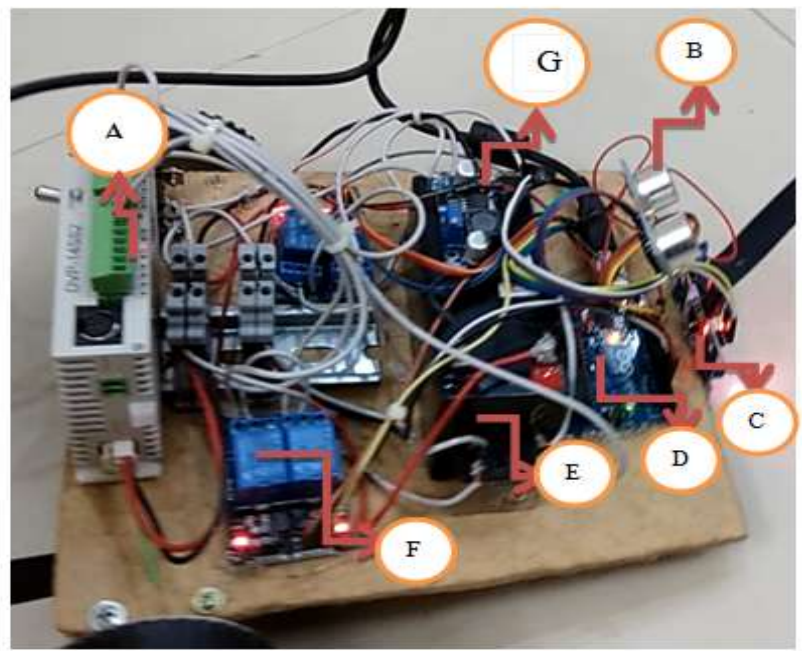

Fig -1: PLC Interfaced AGV components assembly.

$\begin{array}{lll}\text { A } & - & \text { Delta PLC (DVP 14SS2) } \\ \text { B } & - & \text { Ultrasonic Sensor } \\ \text { C } & - & \text { IR Sensors } \\ \text { D } & - & \text { Microcontroller (Arduino UNO) } \\ \text { E } & - & \text { Battery(12V) } \\ \text { F } & - & \text { Relays }(5 \mathrm{~V}) \\ \text { G } & - & \text { Boost convertor }\end{array}$

Infrared sensor are analog sensors which gives a analog output voltage of $3.3 \mathrm{~V}$ to $5 \mathrm{~V}$ which is read by the microcontroller and converted as $5 \mathrm{~V}$ output. Infra Red sensor1(IR1) corresponds to Relay1,Infra Red sensor 2(IR2) corresponds to Relay2,Infra Red sensor 3 (IR3) corresponds to Relay3,Ultrasonic sensor corresponds to Relay4. The $5 \mathrm{~V}$ output signal is sent to the relays and are triggered with $24 \mathrm{~V}$ common. Similarly all the three IR sensors and Ultrasonic sensors values are read and converted to $5 \mathrm{~V}$ signal and is used to trigger 4 relays with 24Vcommon.

\section{Pin Assignment}

A0-IR1 output,A1-IR1 output,A2-IR1 output,10-Ultrasonic echo,11-Ultrasonic Trigger, 4-Relay 1,5-Relay 2,6-Relay 3,7Relay 4Relay1, Relay2, Relay3 and Relay4 are given to PLC's input $\mathrm{X} 0, \mathrm{X} 1, \mathrm{X} 2, \mathrm{X} 3$ and the outputs $\mathrm{Y} 0, \mathrm{Y} 1$ are taken and given to two more relays, which drives the DC motor for the AGV.

\section{Forward Motion}

When relay 1 is on the PLC gets its X0 pin energized and drives both the relays $(5 \& 6)$, by which the AGV moves forward.

\section{Left Motion}

When relay 2 is on the PLC gets its X1 pin energized and drives only the relay6, and holding the relay 5 in Off condition. So this makes the AGV to move in left direction.

\section{Right Motion}

When relay 3 is on the PLC gets its X2 pin energized and drives only the relay5, and holding the relay 6 in Off condition. So this makes the AGV to move in right direction.

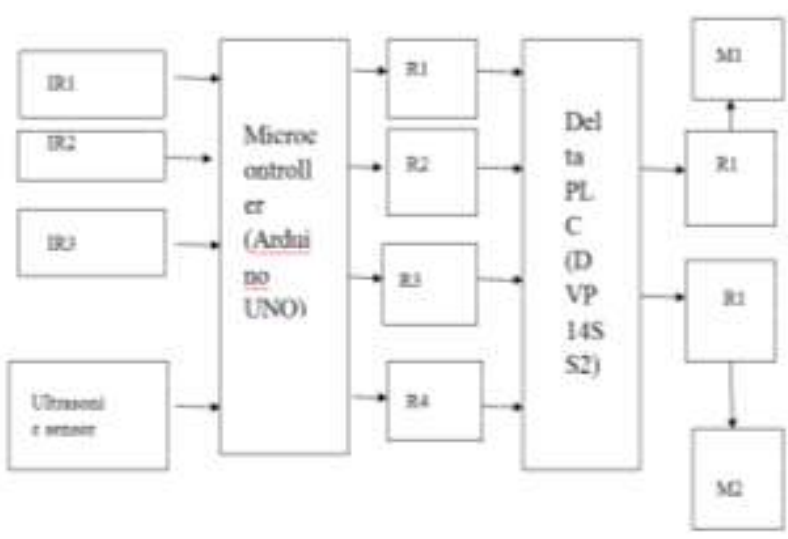

Fig 2: Control system Architecture of AGV Prototype.

\section{Obstacle Detection and Avoidance}

When the ultrasonic sensor is triggered the relay 4 from the microcontroller, gets on by giving the input X3 to PLC. When PLC gets S3 input, it stops both the drives and starts the timer for $15 \mathrm{sec}$ and restarts the AGV based on the current input from IR sensors.

\section{RESULTS AND DISCUSSIONS}

\subsection{Collecting the Utensils at the Desired Table}

In the below scenario hotel like situation has been created with which it consists of one table the Automated Guided Vehicle (AGV) will be moving from initial point through tracking the black path whenever the table(station) arrives then it will halt for 15 seconds still it collects the used utensils and moves to the next station and the movement of the vehicle continues . 


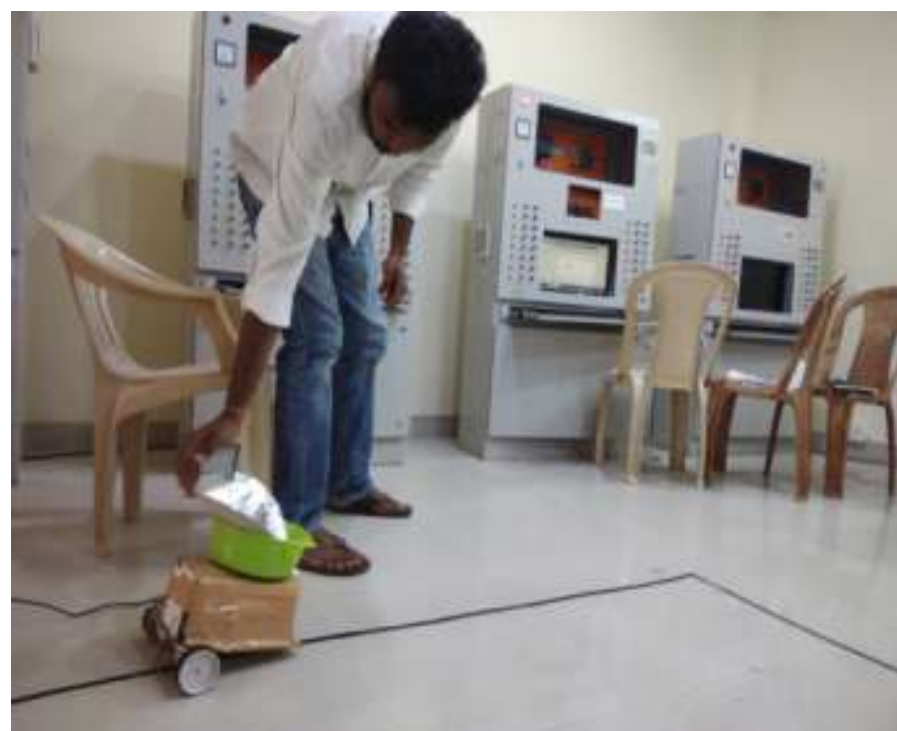

Fig 3: AGV collecting the utensils from the Table1.

\subsection{Obstacle Detection and Avoidance}

When the obstacle in the range of $30 \mathrm{~cm}$ is found the Ultrasonic sensor will trigger the signals so that the PLC will transmit to deduct the movement of the motors and the AGV will halt there for 15 seconds and start to move accordingly .

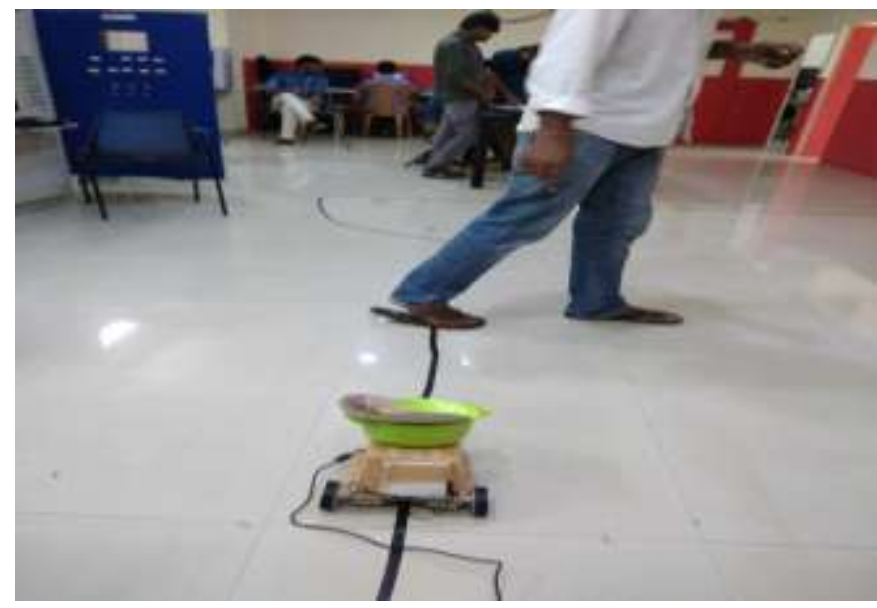

Fig 4: AGV halted for 15 seconds when it senses a obstacle.

\section{PLC PROGRAM}

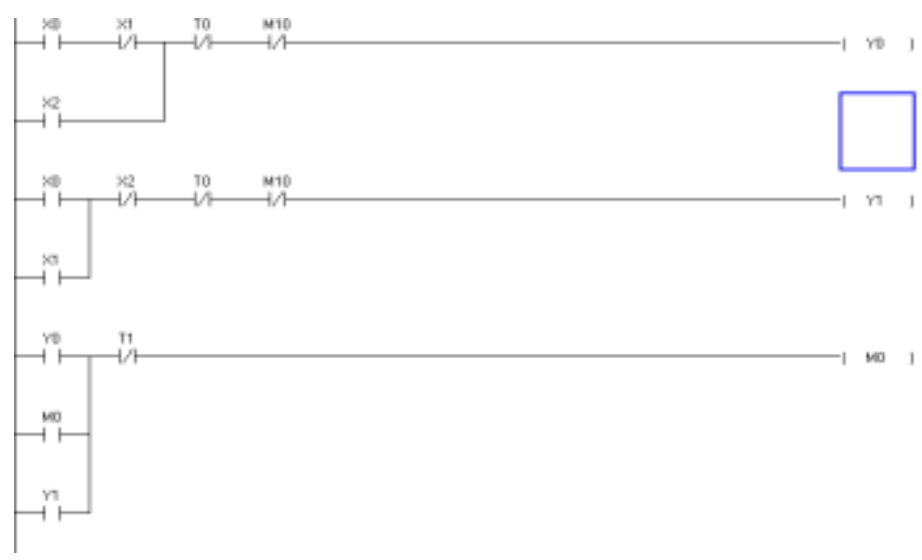

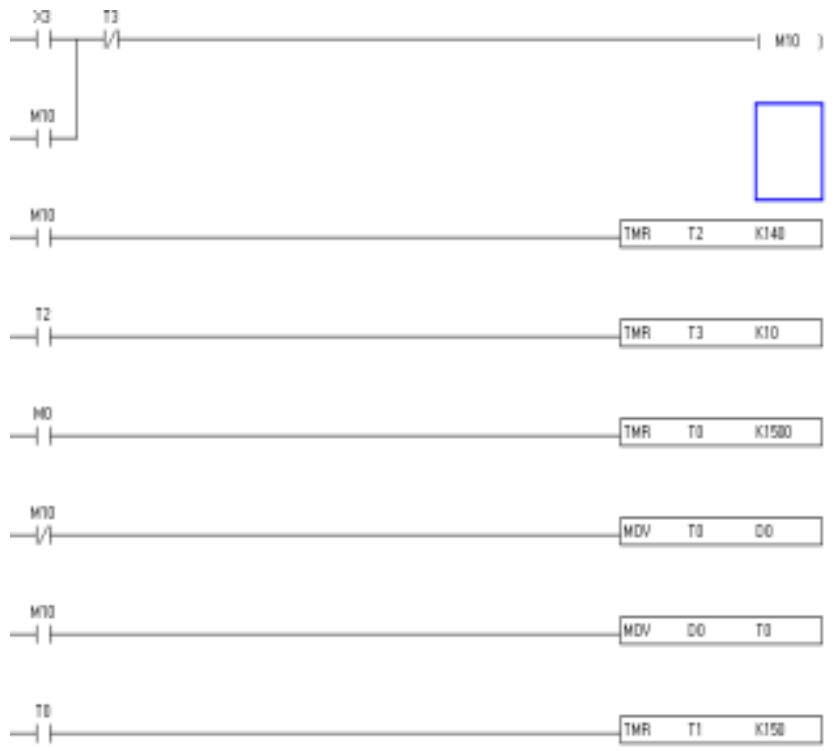

Fig 5: Ladder logic diagram for the AGV

\subsection{PLC Program Explanation}

When X0 is on the plc triggers the both the motors and the AGV runs in forward. So once the Drive starts the timer runs and it counts for 1.30Minutes, using a dummy coil M0. The running time is determined to be 1.30 Minitues and the holding time is said to be $15 \mathrm{Sec}$.When X1 is On the PLC stops the load y0 and starts the motor Y1 so that the AGV moves in Right direction this same concept is applied for Left direction movement also. Left direction is controlled by Pin X2.X3 is the feedback from ultrasonic sensor. Once the ultrasonic sensor is on the AGV stops for $15 \mathrm{secs}$ and starts to move. For this Process we are using two timers. The timer is triggered by a Memory coil(M10) which is latched when the obstacle is sensed. So even though the ultrasonic sensor is on the main timer that is the 1.30Min timer will not get reset, it will be stored in the memory and will be continued. So that the station is reached correctly.

\section{CONCLUSION}

The AGV prototype has got microcontroller and PLC control with the use of relays, sensors and motors for performing automated movement, obstacle detection and avoidance, and intermediate stops at the required stations for collecting used utensils and wastes. The line following or movement is highly dependent on sensors input signals to the controllers which may limits movements at the point of driving a curvature and microcontroller requires a separate power source for its functioning so the sensor and black stripe of technique can be replaced by the magnetic rail technology or even it can be made has randomly moving AGV without any requirement of follower. This AGV prototype is partially avoiding the human intervention in the hotel scenario the used utensils collection and dumping requires the human aid this can be overcome by providing whipping robotic arm to the $\mathrm{AGV}$ and trailer facility to the collector. 


\section{REFERENCES}

[1] J. T. Udding et al Department of Mechanical Engineering, Eindhoven University of Technology, $5600 \mathrm{MB}$, The Netherlands Proceedings of the 18th World Congress The International Federation of Automatic Control Milano (Italy) August 28 September 2, 2000.

[2] Iris F.A. Vis School of Economics and Business Administration, Vrije University Amsterdam, De Boelelaan 1105, Room 3A-31,Amsterdam 1081 HV, The Netherlands Received 9 September 2003; accepted 14 September 2004 Available online 2 November 2004.

[3] Sigal Berman a, EdnaSchechtman, YaelEdan a Department of Gurion university of the Negav,Beer Sheva84-105,Israel b Department of Industrial Engineering and Management, Judea and Samaria College ,Ariel 44-37,Israel,2009.

[4] Atul Tiwari IJSTE - International Journal of Science Technology \& Engineering | Volume 3 | Issue 7 | ISSN (online): 2335-7431, April 2010.

[5] Mudit Sharma International Journal of Engineering and Advanced Technology (IJEAT)ISSN: 2249 - 8958, Volume-2, Issue-1, October 2012.

[6] Suman Kumar das IJSTE - International Journal of Science Technology \& Engineering | Volume 2 | Issue 10 | ISSN (online): 2349-784, April 2016. 